\title{
A RQUITECTURA PARA DOS CARISMAS DISTINTOS EN EL BAJO ARAGÓN TUROLENSE EN EL SEISCIENTOS: EL CONVENTO CARMELITA DE ALCAÑIZ Y EL DESCALZO DEL DESIERTO DE CALANDA ${ }^{1}$
}

JORGE MARTÍN MARCO

Departamento de Historia del Arte. Universidad de Zaragoza jorgemartinmarco@unizar.es

\begin{abstract}
Resumen: En el Bajo Aragón turolense se asentaron un gran número de órdenes religiosas en las primeras décadas del Seiscientos, y entre ellas, los carmelitas, que llegaron a Alcañiz en 1602; y los carmelitas descalzos, que se establecieron en el convento del desierto de Calanda en la década de los ochenta de ese siglo. Sin embargo, las diferencias entre ambos establecimientos son evidentes, ya que fueron concebidos tanto espiritual como arquitectónicamente diferentes uno de otro debido a las funciones que debían cumplir. El caso alcañizano es una de las muestras más destacadas de la arquitectura bajoaragonesa del barroco, mientras que el calandino es un buen ejemplo de desierto carmelita, cuyas trazas probablemente fueron realizadas por artífices de la orden.
\end{abstract}

Palabras clave: Arquitectura barroca / Carmelitas / Trazas / Bajo Aragón / Alcañiz / Calanda.

\section{ARCHITECTURE MADE FOR TWO TYPES OF CHARACTER IN THE 17TH CENTURY TERUEL'S BAJO ARAGÓN: THE CARMELITES CONVENT IN ALCAÑIZ AND THE CARMELITES DISCALCED ONE IN THE DESERT OF CALANDA}

Abstract: A great number of religious orders settled in the Bajo Aragón in Teruel in the first decades of the 17th century, among them the Carmelites that arrived in Alcañiz in 1602; or the Carmelites Discalced, that settled in the convent of the desert of Calanda in the decade of the 80s of that century. However, the differences between both establishments are evident, since they were conceived differently both spiritually and architecturally due to the different function that they had to fulfil. In the case of Alcañiz, it is one of the most prominent samples of the architecture of the Bajo Aragón in the Baroque period, while in Calanda's case, it is a good example of Carmelite desert, the design of which was probably made by authors of the order.

Key words: Baroque architecture / Carmelites / Traces / Bajo Aragón / Alcañiz / Calanda.

Entre finales del siglo XVI y las primeras décadas de la centuria siguiente se instalaron en el Bajo Aragón un abundante número de órdenes religio- sas. ${ }^{2}$ Al establecimiento de las monjas dominicas en el convento de San Gregorio de Alcañiz en $1593^{3}$ le siguieron las fundaciones de los carmelitas

\footnotetext{
* Fecha de recepción: 15 de abril de 2019 / Fecha de aceptación: 14 de diciembre de 2019.

1 Trabajo realizado en el marco del Proyecto de Investigación I+D "Los diseños de arquitectura de tradición gótica en la Península Ibérica entre los siglos XVII y XVIII. Inventario y catalogación" (HAR2017-85523-P). Forma parte de la tesis doctoral del autor sobre arquitectura religiosa en Aragón durante los siglos XVII y XVIII bajo la dirección del doctor Javier Ibáñez Fernández (Universidad de Zaragoza) y la doctora Yolanda Gil Saura (Universitat de València).

2 El autor desea agradecer a María Lacueva y Juan Membrado su compañía en la visita al convento de Calanda; a Vicente Dobato y Paz Benavente su amabilidad a la hora de realizar las fotografías de la iglesia del Carmen de Alcañiz, y a sus directores de tesis todas las apreciaciones y correcciones que han realizado al texto.

${ }^{3}$ Aunque en un principio el convento iba a ser ocupado por religiosas de Santa Clara, los jurados de la localidad determinaron finalmente que fueran las dominicas quienes debían instalarse en 1593. Sobre la fundación de este convento, véase lo anotado por Mariano Ardid y Plano en 1852 [Biblioteca Municipal de Alcañiz (B.M.A.), ARDID Y PLANO, Mariano, 1852, ff. 124v-128r].
} 
en $1602 ;{ }^{4}$ y la de los capuchinos diez años más tarde, ${ }^{5}$ y aunque su iglesia y las dependencias conventuales ya estaban edificándose bajo la dirección del cantero Pablo Galán en $1617,{ }^{6}$ no fueron concluidas hasta las intervenciones de Domingo Burchel -los trabajos de cantería7- en 1629 y de Pedro Gascón y sus hijos -los trabajos de albañilería- un año después. ${ }^{8}$ También por estas fechas se fundaron conventos en algunas poblaciones de alrededor, como el de la Purísima Concepción y San Roque de religiosas clarisas en Valdealgorfa por Diego de Ramellore -canónigo de la metropolitana de Zaragoza- en el año 1619 [Fig. 1], ${ }^{9}$ o el de la Virgen de Gracia de franciscanos mínimos de La Fresneda, que fue fundado a finales de la centuria anterior, ${ }^{10}$ pero su construcción se prolongó durante las primeras décadas del Seiscientos, como demuestra que la iglesia todavía seguía sin concluirse en 1620, ${ }^{11}$ aunque los trabajos en el convento ya habían finalizado para 1639 , cuando el procurador de los religiosos nombró árbitros a Domingo Zapata y a Diego Borbón -albañiles de Zaragoza- para dirimir las diferencias entre los mínimos y el albañil Pablo Hernández por una obra que este había realizado en el convento. ${ }^{12}$

Algunas órdenes como la Compañía de Jesús o los cartujos también tantearon instalarse en el territorio. Los primeros pretendieron fundar en el Bajo Aragón dos establecimientos, uno en Alcañiz, gracias al legado testamentario de Miguel Jerónimo
Rastavens en $1623,{ }^{13}$ y otro en Aguaviva por impulso de Jaime Cases un año después; ${ }^{14}$ mientras que los segundos solicitaron al concejo de Alcañiz instalarse en sus términos en febrero de $1638,{ }^{15}$ para lo cual los jurados de la localidad cedieron al padre Lorenzo de Clavería -prior del combento de la orden de la cartuxa de las Fuentes en el presente reyno de Aragon- un terreno para hazer y edifficar dicho convento situado encima [del] puntarron de camino de Alcorissa, aunque la guerra de Cataluña frustró los planes iniciales, y acabaron trasladándose a su actual emplazamiento en las inmediaciones de Zaragoza en 1640. ${ }^{16}$

En otras localidades bajoaragonesas, como Calanda, la llegada de órdenes religiosas fue mucho más tardía que en el resto del territorio. En efecto, uno de los primeros impulsos fue el realizado por Antonio Cascajares, que solicitó permiso al concejo de la localidad en nombre de Sabina Maura Rodríguez -su esposa- para fundar un convento de carmelitas descalzas junto a la iglesia del Pilar a finales de mayo de $1677 .{ }^{17}$ El patrocino de Sabina Maura Rodríguez resultó fundamental para el desarrollo de las obras del convento, cuya fábrica estaba ya muy adelantada para $1690,{ }^{18}$ y para su conclusión definitiva recibió un nuevo impulso económico gracias a un donativo de seis mil escudos siete años después. Sin embargo, la muerte de Sabina Maura Rodríguez, la llegada de los carmelitas descalzos al convento de la Torre de Al-

${ }^{4}$ GONZÁLEZ HERNÁNDEZ, Vicente, 1994, p. 49.

${ }^{5}$ TABOADA CABAÑERO, Eduardo Jesús, 1969, p. 112.

${ }^{6}$ El mercader alcañizano Melchor Sierra, que además era el síndico de los frailes capuchinos, requirió al cantero Pablo Galán, habitante en Alcañiz, sobre los trabajos que estaba realizando en la iglesia y en el convento [Archivo Histórico de Protocolos de Alcañiz (A.H.P.A.), Miguel Joan Cervera, 1617, ff. 55r-62v (Alcañiz, 23-IV-1617)].

7 MARTín MARCO, Jorge, 2018, p. 103, nota 76.

8 GONZÁLEZ HERNÁNDEZ, Vicente, 1994, pp. 71-72.

9 La institución y dotación del monasterio en LEÓN PACHECO, Carmen, 2007, doc. 6-7943 (8774), pp. 130-139.

10 JULVE, Enrique y CUELLA, Ovidio, 1986, pp. 79-82.

11 DE MIGUEL LOU, Gloria, 2005, doc. 3-3680 (4239), p. 110.

12 Archivo Histórico de Protocolos Notariales de Zaragoza (A.H.P.N.Z.), Ildefonso Moles, 1639, ff. 2006r-2016r (Zaragoza, 17-XI1639). Documento referenciado, con una interpretación que no compartimos, en GRANADOS BLASCO, Ma del Carmen, 2007, doc. 9-2589 (2713)

13 MARTÍNEZ ORTIZ, José, 1960, pp. 189-197.

14 IBÁÑEZ FERNÁNDEZ, Javier; CRIADO MAINAR, Jesús, 2012, p. 397.

${ }^{15}$ Además, el prior, para tomar verdadera possesion del lugar, se passeo por [el terreno] a caballo en su mula y mando a un criado suyo el coxer una mata de romero. Ese día se produjo el acto publico de avecindamiento de los padres cartuxos [A.H.P.A., Pedro Isidro Portolés, 1638, ff. 2r-3v y 4r-5r (Alcañiz, 11-II-1638)].

${ }^{16}$ BARLÉS BÁGUENA, Elena, 2014, pp. 331-333.

17 CEAMANOS LLORENS, Roberto; MATEOS ROYO, José Antonio, 2005, p. 151.

18 Las obras fueron tasadas por Jacinto de Cascajares y Blancas, infanzón y alcaide de la villa de Calanda, y Francisco Mesa, carpintero, natural de la villa de La Almunia y residente en Calanda [A.H.P.A., Faustino Roque Gómez, notario de Calanda, 1690, ff. 84v-85v (Calanda, 13-V-1690); CEAMANOS LLORENS, Roberto; MATEOS ROYO, José Antonio, 2005, p. 151]. 
ginés, Ginés o del Desierto y el estallido de la Guerra de Sucesión truncaron los planes iniciales. ${ }^{19}$ Con la excepción de los descalzos -de los que nos ocupamos más adelante- los últimos en establecerse en la localidad fueron los frailes capuchinos. Tras obtener los permisos pertinentes de las autoridades civiles, ${ }^{20}$ fray Antonio Gallur -provincial de la orden en Aragón- otorgó poderes para fundar y construir el nuevo convento en Calanda el 27 de marzo de 1758:21 y varios meses después -el 2 de septiembre- José Antonio de Cascajares y Herla como heredero de su padre, y posehedor de su mayorazgo, y con calidad de executor testamentario [y como pertenecía] a mi dicho otorgante el patronato de el convento de capuchinos de la villa de Calanda, concedió poderes a Juan Francisco de Gracia y a Jacinto Cascajares -canónigos de la metropolitana de Zaragoza-, a Pedro Joaquín de Pedro y Cascajares, José Trullench y Cascajares y a Joaquín de Pedro y Ara -vecinos de Alcañiz- para que pudieran convenir y concordar con los capuchinos de Aragón todo quanto fuere util, combeniente, y necesario en punto de dicho mi patronato y también para realizar la cesion, ô, cesiones de el edificio convento y casa que oy existe cerca, ô quasi contigua a Nuestra Señora del Pilar de Calanda; ${ }^{22}$ aunque finalmente los religiosos no se instalaron en este lugar, y acabaron construyendo un nuevo convento en la partida denominada eras de las Peñetas. ${ }^{23}$

\section{El largo proceso constructivo del convento carmelita de Alcañiz}

La llegada de los frailes carmelitas a Alcañiz se produjo en 1602, después de que fray Gaspar Cortés -representante del provincial de los carmelitas fray Francisco Sifre- consiguiera la licencia pertinente por parte de las autoridades eclesiásticas -arzobispado de Zaragoza y cabildo de la colegiata

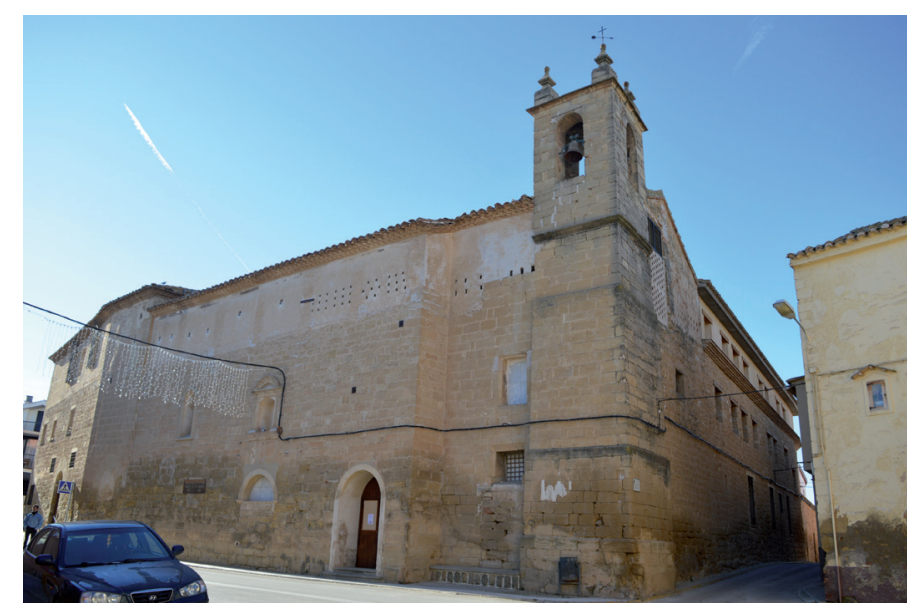

Fig. 1. Valdealgorfa, Teruel. Convento de la Purísima Concepción y San Roque. Exterior.

de Alcañiz ${ }^{24}$ - para su instalación en las casas de Ramón de Santa Pau y Cavaller, situadas en la parroquia de San Juan; ${ }^{25}$ aunque la compra de estas propiedades -unas casas suias con los corrales y güerto a ella contiguas y apegadas- por doscientos sesenta sueldos no se llevó a cabo hasta enero del año siguiente. ${ }^{26}$ Los restos de la casa de Santa Pau -probablemente del siglo XVI- resultan fácilmente identificables, ya que constituyen el muro de cierre de la nave de la Epístola de la iglesia con la calle del Carmen.

Las primeras obras documentadas que se realizaron fueron las tapias y paredes del convento, es decir, la cerca; una empresa que llevaron a cabo los albañiles Miguel Cubeles -vecino de la villa de Alcañiz- y Miguel Olaso -domiciliado en Escatronpor dos mil sueldos jaqueses a partir del mes de marzo de 1624. ${ }^{27}$ Sin embargo, los frailes carmelitas

19 CEAMANOS LLORENS, Roberto; MATEOS ROYO, José Antonio, 2005, p. 152.

20 CEAMANOS LLORENS, Roberto; MATEOS ROYO, José Antonio, 2005, p. 154.

21 A.H.P.N.Z., José Domingo Asín, 1758, ff. 75r-76v (Zaragoza, 27-III-1758).

22 A.H.P.N.Z., Gaspar Borao de Latas, 1758, ff. 145v-146r (Zaragoza, 2-IX-1758).

23 CEAMANOS LLORENS, Roberto; MATEOS ROYO, José Antonio, 2005, p. 154.

${ }^{24}$ GONZÁLEZ HERNÁNDEZ, Vicente, 1994, p. 49. Además, fray Gaspar Cortés también estuvo ligado a la fundación del convento de carmelitas de Tudela (AZANZA LÓPEZ, José Javier, 1998b, p. 302).

25 Santa Pau también adquirió las casas del labrador Joan Martín e Isabel Lombart por cuatro mil seiscientos sueldos el 13 de febrero de 1603; una cantidad que Santa Pau otorgó tener en comanda, y que el labrador prometió no ayudarse de ella en caso de que el prior y los frailes del convento del Carmen no le pagasen los cuatro mil sueldos para el mes de agosto de 1604 [A.H.P.A., Joan Loscos, 1603, ff. 21r-22r (Alcañiz, 13-II-1603)].

26 GONZÁLEZ HERNÁNDEZ, Vicente, 1994, p. 49.

27 Miguel Cubeles otorgó tener dos mil sueldos en comanda de Olaso ese mismo día [A.H.P.A., Joan Thomas de Barberán, 1624, ff. 50v-51r (Alcañiz, 6-III-1624)]; una cantidad de la que Olaso prometió no valerse en caso de que Cubeles no le diera la obra realizada [ff. 51v-52r, apéndice documental, doc. 1]. Ese mismo día, Miguel Olaso otorgó tener dos mil sueldos en 
se encontraron con problemas económicos durante la prosecución de las obras. Por este motivo, fray Martín Sánchez del Castellar -prior del convento- se dirigió a fray Joan Pinto de Vitoria -provincial de la orden- exponiendo que debido a la necessidad grande que [tenía] aquel convento de abitacion para los religiosos, y que a pesar de que tenían dos quartos empesados, no podían concluirlos debido a la falta de numerario, ${ }^{28}$ así que para poder finalizar esta empresa, el provincial de la orden expidió la licencia pertinente para que el convento alcañizano pudiera cargarse un censal por valor de doscientos sueldos jaqueses de pensión anual en favor de Miguel Valero -mercader alcañizano- el 27 de junio de 1629, y que habrían de hacerse efectivos para el día de San Pedro Apóstol -el 29 de junio- del año siguiente. ${ }^{29}$

En cuanto a la fábrica del templo, ya debía de estar bastante avanzada para el año 1645, cuando los religiosos, argumentando que había muchas personas devotas y principales que deseaban ser patrones de las capillas de la iglesia que en dicho convento se [estaba] edificando, solicitaron el permiso a fray Martín Ximénez de Embún -provincial de la orden carmelita en Aragón, Valencia y Navarra- para donar las capillas y sepulturas del templo; algo que el religioso acabó concediendo a los carmelitas, ${ }^{30}$ quienes asignaron la capilla bajo la advocación de la Virgen del Pilar al platero Pedro Sabogal el 14 de septiembre de ese mismo año. ${ }^{31}$ No obstante, la iglesia todavía no se había concluido hacia los años setenta del Seiscientos, cuando el notario alcañizano Pedro Juan Zapater, en su obra titulada La Thesorera, señaló que por aquel entonces todavía faltaba por construir el coro y el último tramo de la nave, y que, una vez concluida, habría de ser una de las mejores [igle- sias] de esta ciudad. ${ }^{32}$ A esta época debe adscribirse la hornacina situada en el lateral de la iglesia que recae la calle del Carmen -restaurada recientemente- donde aparece la fecha de 1669.

Sin embargo, la finalización del templo se demoró hasta la última década del siglo. Para entonces, los carmelitas, junto con Francisco Gazulla, un mercader alcañizano que contribuyó con numerosos donativos a la fábrica del convento, capitularon con el cantero Antonio Estrada -habitante en la ciudad de Alcañiz- la realización de la obra del frontispicio y coro ante el notario Pedro Juan Zapater en 1693, y por la que cobró quinientas sesenta libras, once sueldos y ocho dineros el 5 de abril de 1695. ${ }^{33}$ Un año después -el 19 de febrero de 1694- las mismas partes convinieron la construcción de la torre campanario de la iglesia. ${ }^{34} \mathrm{La}$ capitulación exigía la realización de dos cuerpos cuadrados de sillería y un tercero de planta ochavada, en cuyas cuatro esquinas debía construir quatro piramides, y sobre el que habría de voltearse una copa, o, media naranja de piedra picada. Antonio Estrada aceptó realizar estos trabajos por doscientas cincuenta libras -cincuenta de parte de los carmelitas y las restantes doscientas de parte de Francisco Gazulla- y, además, los religiosos le concedieron un sitio suficiente devajo del coro para realizar el baso de entierro para él y su familia.

Finalmente los carmelitas abordaron la finalización de la nave y el tramo de los pies con Gerónimo Gascón el 20 de enero de 1697. ${ }^{35}$ Este acuerdo preveía cubrir la ultima navada que [correspondía] a la puerta principal mediante la construcción de un tejado similar a los dispuestos en el resto del templo; la realización de un arco próximo a la pared foral, arrimado a ella; y que, junto con el

comanda de Cubeles [A.H.P.A., Joan Thomas de Barberán, 1624, f. 53r (Alcañiz, 6-III-1624)]; una cantidad que Cubeles prometió no valerse salvo en el caso de que Olaso no terminase la obra [A.H.P.A., Joan Thomas de Barberán, 1624, ff. 53v-55r (Alcañiz, 6-III-1624), apéndice documental, doc. 2].

${ }^{28}$ A.H.P.A., Lorenzo Vililla, 1629, ff. 386r-389v (Alcañiz, 27-VI-1629), apéndice documental, doc. 3.

${ }^{29}$ A.H.P.A., Lorenzo Vililla, 1629, ff. 388r-389r.

30 A.H.P.A., Juan Francisco Vililla, 1645, ff. 356v-361r (Alcañiz, 14-IX-1645). También en GONZÁLEZ HERNÁNDEZ, Vicente, 1994, p. 52.

${ }^{31}$ GONZÁLEZ HERNÁNDEZ, Vicente, 1994, p. 53.

${ }^{32}$ Algunas de las referencias que aporta el autor, cotejadas con la documentación notarial conservada, invitan a pensar que la obra se escribiera en torno al último tercio del siglo XVII [Biblioteca de la Real Academia de la Historia (B.R.A.H.), ZAPATER Y SANCHO, Pedro Juan, 1704].

${ }^{33}$ A.H.P.A., Pedro Juan Zapater y Sancho, 1695, ff. 182v-183r (Alcañiz, 5-IV-1695), apéndice documental, doc. 4. Documento referenciado en GONZÁLEZ HERNÁNDEZ, Vicente, 1994, p. 61.

${ }^{34}$ A.H.P.A., Pedro Juan Zapater y Sancho, 1694, ff. 89v-94r (Alcañiz, 19-II-1694). Documento parcialmente publicado en GONZÁLEZ HERNÁNDEZ, Vicente, 1994, pp. 57-61.

35 A.H.P.A., Pedro Juan Zapater y Sancho, 1697, ff. 82r-89r (Alcañiz, 20-I-1697). Documento publicado parcialmente en GONZÁLEZ HERNÁNDEZ, Vicente, 1994, pp. 61-64. 
que debía dividir este último tramo del resto de la nave, habría de cortarlos con labores principales de talla, ${ }^{36}$ es decir, que debía aplicar un tipo de decoración en relieve -realizada con yeso- y que aunque el acuerdo no especificaba de qué tipo, Gascón terminó aplicando una serie de motivos vegetales. La capitulación también prescribía raspar todas las paredes de la fabrica, el volteo de la bóveda del coro -capialcadas (sic) segun arte de buena arista- y su decoración mediante la colocación de tres florones, uno en medio -de ocho palmos- y los otros dos -de seis palmos- en las aristas. Finalmente, los últimos trabajos que exigía el contrato se referían al acabado del interior mediante la colocación de tarjones e impostas alrededor del templo, al enmaderamiento del suelo del coro, a la colocación de los balaustres en el antepecho de esta estructura, al enladrillado del suelo y también debían rematarse algunas partes del edificio. Gascón, que debía entregar la obra acabada para el mes de junio o como muy tarde asta el dia de San Miguel de setiembre de ese mismo año, aceptó realizarla por dos mil ochocientos cuarenta sueldos pagaderos dos tercios en dinero y el otro [tercio] en frutos.

En cualquier caso, la fábrica de la iglesia ya estaba totalmente concluida el 10 de octubre de $1702 .^{37}$ Ese día, los religiosos, Francisco Gazulla y Antonio Estrada hicieron relación de las obras que habían contratado -frontispicio, coro y torre de las campanas-, y como Estrada había cumplido enteramente en haver hecho las dichas obras y fabricas y los religiosos y Gazulla le habían satisfecho todas las cantidades de dinero pactadas, dichas partes declararon y reconocieron haver cada una cumplido con lo que [estaba] a su cargo en virtud de las capitulaciones, tratas, y conciertos.

Posteriormente, la atención de los religiosos recayó en la ornamentación del interior. Para ello, Francisco Gazulla estableció una cláusula en su primer testamento -ordenado en Alcañiz el 15 de septiembre de $1694^{38}$ - en la que destinó cuarenta y cuatro mil sueldos para el retablo del altar maior asi para escultura como para dorarlo. ${ }^{39}$ Sin embargo, en sus últimas voluntades -redactadas también en Alcañiz el primero de mayo de $1709^{40}$ - Gazulla legó a los religiosos diez mil reales de plata para la construcción de un retablo de mazoneria para su altar maior con obligacion de celebrarme sus religiosos dos mil misas rezadas por mi alma por una vez tan solamente. ${ }^{41}$ Los carmelitas, que recibieron quinientas libras de parte de los ejecutores testamentarios de Gazulla en $1715,{ }^{42}$ contrataron la realización del retablo mayor con el escultor Jaime Nogués el 2 de enero del año siguiente. ${ }^{43}$ El mueble ya estaba totalmente concluido el 3 de mayo de $1717,{ }^{44}$ y para entonces, los carmelitas y Jaime Nogués nombraron visores a los escultores José Ochando -de Villarreal (Castellón) ${ }^{45}$ - y a Martín Villabona -de Belchite (Zaragoza) ${ }^{46}$ - respectivamente, quienes emitieron su parecer sobre el retablo dos días después, ${ }^{47}$ y que acabó siendo aceptado por ambas partes el 19 de mayo de ese mismo año. ${ }^{48}$ Este no fue el único encargo que Nogués

36 Sobre este tipo de decoración en las bóvedas tabicadas, véase IBÁÑEZ FERNÁNDEZ, Javier, 2010, p. 369; IBÁÑEZ FERNÁNDEZ, Javier, 2012, p. 86; IBÁÑEZ FERNÁNDEZ, Javier, 2013, p. 57.

37 A.H.P.A., Pedro Juan Zapater y Sancho, 1702, ff. 520v-524r (Alcañiz, 10-X-1702), apéndice documental, doc. 5.

38 A.H.P.A., Pedro Juan Zapater, 1694, ff. 445r-449r (Alcañiz, 15-XI-1694).

39 Ittem para fenecida la vida de dicha Vicenta Viñas mi muger quiero y es mi voluntad se den de mis bienes y hacienda al convento de Nuestra Señora del Carmen de dicha ciudad de Alcañiz quarenta y quatro mil sueldos jaqueses para hacer el retablo del altar maior asi para escultura como para dorarlo, con obligacion de hacerme celebrar ochocientas misas traçadas por mi alma y a mi intención asi en dicho convento como en los demas de la probincia con esta advertencia que si yo dicho testador entregare dicha cantidad para hacer dicho retablo y dorarlo en tal caso quiero con esta obligacion y si solamente hubiere entregado algunas partida, o, partidas sin haver acabado de dar el intento cumplimiento en tal caso se haian /447 r/ de admitir en quenta para dicho convento la cantidad que arriba señalo (...) [A.H.P.A., Pedro Juan Zapater, 1694, ff. 446v-447r].

40 A.H.P.A., Pedro Juan Zapater y Sancho, 1709, ff. 59r-62v (Alcañiz, 1-V-1709).

41 A.H.P.A., Pedro Juan Zapater y Sancho, 1709, f. 59v.

42 THOMSON LLISTERRI, Teresa, 1998, doc. 28, pp. 289-290.

43 THOMSON LLISTERRI, Teresa, 1998, p. 114.

44 THOMSON LLISTERRI, Teresa, 1998, doc. 29, pp. 293-295.

45 Sobre la trayectoria profesional de José Ochando, véase YEGUAS I GASSÓ, Joan, 2012, pp. 39-48.

${ }^{46}$ Algunos datos sobre la trayectoria profesional de Villabona fueron publicados en FRANCO AUGUSTO, Jesús Manuel, 1987, pp. 183-206.

47 Documento parcialmente publicado en GONZÁLEZ HERNÁNDEZ, Vicente, 1994, pp. 65-67; e íntegramente como inédito en THOMSON LLISTERRI, Teresa, 1998, doc. 30, pp. 297-299.

48 THOMSON LLISTERRI, Teresa, 1998, doc. 31, pp. 301-302. 


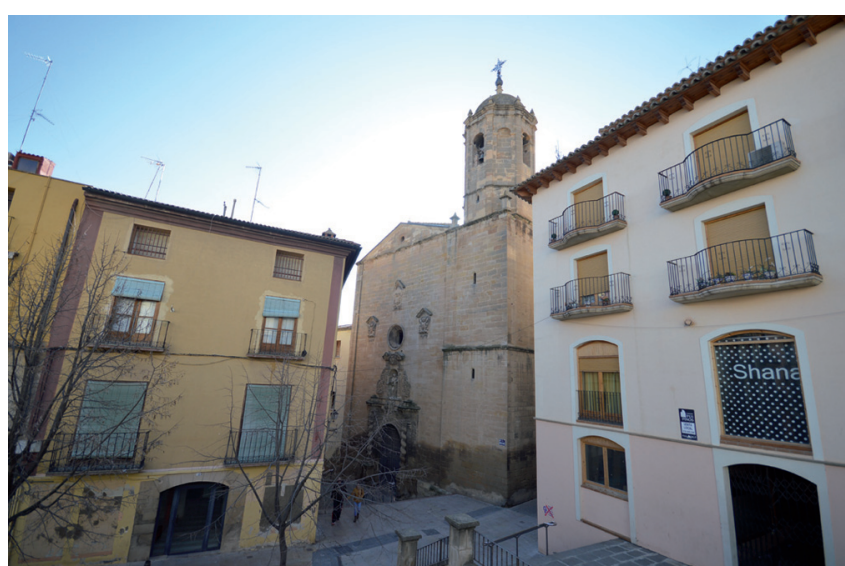

Fig. 2. Alcañiz, Teruel. Iglesia del Carmen. Exterior.

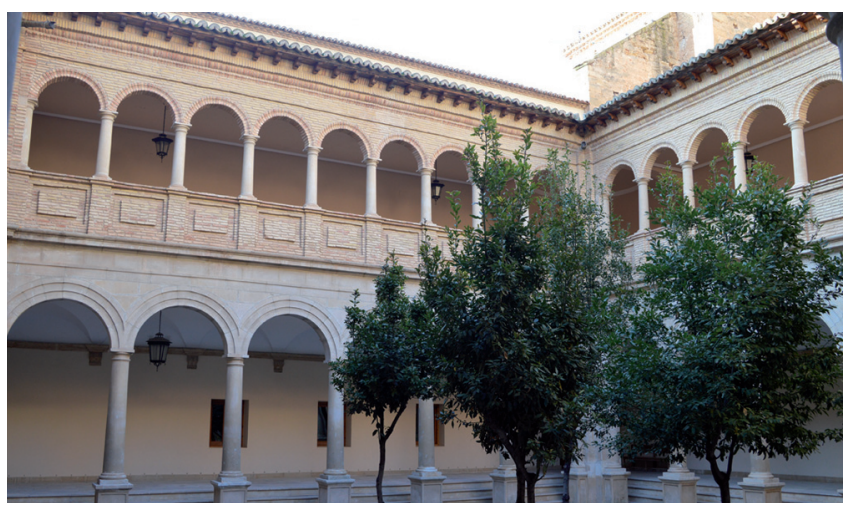

Fig. 3. Alcañiz, Teruel. Iglesia del Carmen. Claustro, actual Palacio de Justicia.

asumió en la iglesia de los carmelitas, ya que también se ocupó de la realización de un retablo dedicado a Santa Orosia destinado al altar advocado a la santa pirenaica, que fue costeado por el cantero Vicente Gabás y su esposa Ana Destre, tal y como consta en las últimas voluntades de ella -redactadas en Alcañiz el 27 de abril de 1729- ${ }^{49}$ don- de indicó, entre otras cosas, que se [cumpliese y ejecutase] dicho retablo pagandose de mis vienes la mitad de el dicho ymporte y cantidad ajustada que es veinte $y$ siete libras y diez sueldos. ${ }^{50}$

El templo, construido en piedra sillar y mampostería, sigue un esquema general de planta basilical de tres naves de altura desigual; la central, cubierta con bóvedas de cañón con lunetos y las laterales con arista. Cuenta con coro alto a los pies, carece de transepto y la cabecera -de perfil recto al exterior- se cierra al interior mediante una bóveda en forma de venera. La torre campanario se levanta a los pies del edificio [Fig. 2].

El claustro -situado en el lado sur de la iglesia- es de planta cuadrada y está dividido en dos alturas. La inferior, construida íntegramente en sillería, se compone de una galería de arcos de medio punto que apean sobre columnas toscanas de fuste liso y plintos de gran tamaño, mientras que la superior se articula también mediante una galería de arcos de medio punto -pero construida en ladrillo- y que apean en columnas pétreas de orden toscano. En los encuentros entre las cuatro pandas del recinto se voltean unas bóvedas vaídas en cuyos arcos se despliega toda una decoración de tipo geométrico, de lazo, vegetal y figurativo [Fig. 3].

Algunos de los elementos constructivos y decorativos presentes en el convento alcañizano son un buen reflejo del panorama arquitectónico bajoaragonés del momento. Así, cuestiones como la decoración geométrica y de lazo de raíz serliana, ${ }^{51}$ que puede descubrirse en el intradós de los arcos de las cuatro bóvedas vaídas de los encuentros de las crujías del claustro, o en los arcos fajones de la nave de la iglesia, también se emplearon en otros edificios cercanos, como en la iglesia de la Natividad de Andorra -construida por Juan Rigor entre 1597 y $1609^{52}$ - y en otros ejemplos más alejados geográficamente pero construidos por artífices asentados en el Bajo Aragón -y de raíces francesas ${ }^{53}$ - como la iglesia de los dominicos de Forcall (Castellón), cuyas obras fueron contratadas con el cantero Beltrán Estrada y el albañil Joan Barta en 1654. ${ }^{54}$

\footnotetext{
49 A.H.P.A., Pablo Alberto Suñer, 1729, ff. 86r-88r (Alcañiz, 27-IV-1729).

50 Ittem por quanto el dicho Vicente Gavas mi marido, $y$ yo dicha testadora tenemos ofrecido por devocion hacer en el dicho combento de Nuestra Señora del Carmen un retablo, y altar de Santa Orosia, y con efecto tenemos ajustado y combenido su ymporte con Jayme Nogues maestro escultor vezino de esta ciudad en cantidad de cinquenta y cinco libras jaquesas. Por tanto quiero y es mi voluntad que se cumpla y execute dicho retablo pagandose de mis vienes la mitad de el dicho ymporte $y$ cantidad ajustada que es veinte y siete libras y diez sueldos [A.H.P.A., Pablo Alberto Suñer, 1729, f. 87r].

51 Los modelos aparecen recogidos en SERLIO, Sebastiano, 1552, lib. IV, cap. IX, f. LXXVIr.

52 ALQUÉZAR VILLARROYA, Cristina; LÓPEZ BIELSA, Rosario, 2014, pp. 39-47.

53 MARTÍN MARCO, Jorge, 2018, p. 103.

${ }^{54}$ EIXARCH FRASNO, Josep, 1994, pp. 293-306.
} 
La portada principal está situada a los pies del edificio, y su acceso se realiza a través de un arco de medio punto flanqueado por columnas salomónicas. $^{55}$ El uso de este elemento en el panorama artístico del territorio ha podido documentarse, por lo menos, desde el retablo de la Virgen del Rosario de la iglesia parroquial de Calanda, contratado por la cofradía del mismo nombre con los escultores Juan de la Torre y Jusepe Alastuey en $1656 ;{ }^{56}$ pero todavía hubo que esperar bastantes años para que irrumpiera en el panorama arquitectónico bajoaragonés. En efecto, el primer ejemplo es la portada de la iglesia parroquial de Alcorisa, probablemente ampliada -y adaptada a los nuevos gustos barrocos- de la mano de Pedro Cuyeo en $1688 .{ }^{57}$ A ella le siguieron las de los carmelitas alcañizanos y las iglesias parroquiales de Valdealgorfa -entre $1700 \mathrm{y}$ $1706-{ }^{58}$ y Calaceite $-1706-; 59$ la ermita de la Virgen del Agua de Castellote $-1718-,{ }^{60}$ o las de Belmonte de San José, ${ }^{61}$ Beceite, $^{62}$ La Codoñera, Mas de las Matas o Valjunquera, realizadas en torno a la década de $1730 .^{63}$ En el hastial, además, también se disponen tres escudos de la orden del Carmelo cobijados por sendos tejadillos a dos aguas.

Otro de los rasgos característicos del templo alcañizano es la bóveda avenerada que cierra el altar mayor [Fig. 4]. Esta estructura, tal y como han señalado algunos autores, podría ser la traslación en yeso de soluciones tipológicas similares realizadas en piedra durante el Quinientos. ${ }^{64}$ En Aragón

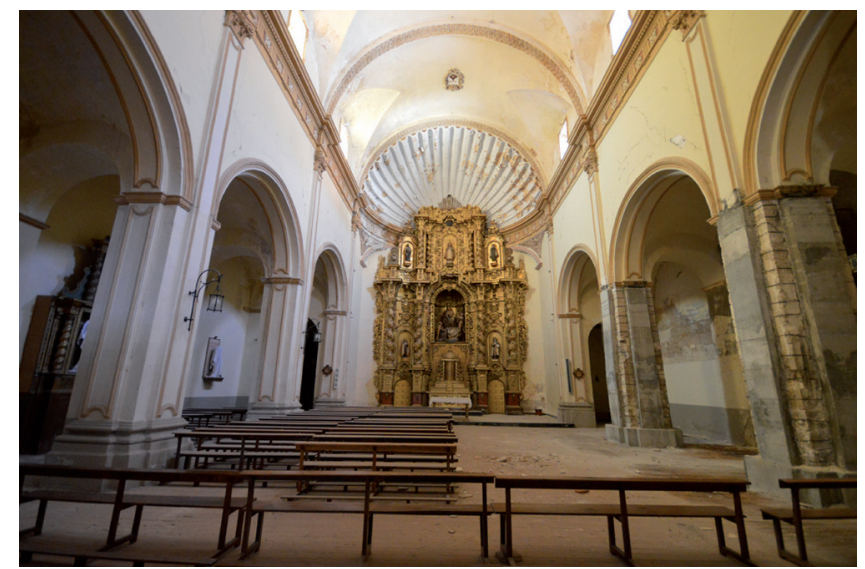

Fig. 4. Alcañiz, Teruel. Iglesia del Carmen. Interior.

se venía utilizando en ejemplos como la capilla mayor de la iglesia de Maleján (Zaragoza), realizada en la tercera década del Seiscientos; ${ }^{65}$ en la iglesia del convento de San Roque de Calamocha (Teruel), ejecutada por Pedro Girón hacia 1647;66 en la de Santo Domingo de Silos de Daroca (Zaragoza), cuya reforma se produjo entre 1688 y 1689 y donde estaba prevista la construcción de una concha en el presbiterio, aunque finalmente se volteó una bóveda de cuarto de esfera lisa; ${ }^{67}$ o en la iglesia parroquial de Olocau del Rey (Castellón),

55 Esta portada fue reproducida en Pueblo Español de Barcelona con motivo de la exposición celebrada en esa ciudad en 1929 (GRANDAS SAGARRA, Carme, 2006, pp. 105-123).

${ }^{56}$ El contrato preveía la realización de seis columnas salomónicas entre las hornacinas aveneradas que debían alojar las imágenes de la titular -en el centro- y las de Santo Domingo y San Francisco a los lados [A.H.P.A., Joseph Peralta, notario de Calanda, 1656, ff. 109v-112r (Calanda, 6-VI-1656). Documento referenciado en CEAMANOS LLORENS, Roberto y MATEOS ROYO, José Antonio, 2005, p. 156, nota 77].

57 El documento de la participación de Cuyeo en Alcorisa fue regestado en ALMERÍA, José Antonio, 1983, p. 51; y publicado en RINCÓN GARCÍA, Wifredo, 1990, doc. 11, p. 216.

${ }^{58}$ Las obras fueron iniciadas por Juan de Lorita en 1700, que acabó traspasándolas a Ignacio de Aramburu seis años después (THOMSON LLISTERRI, Teresa, 1998, pp. 289-290).

59 El autor de la portada fue Francisco de Ibargüens (PÉREZ TEMPRADO, Lorenzo, 1908; 1982, p.16).

${ }^{60}$ Es probable que Jaime Asensio, maestro natural de Las Parras de Castellote, interviniera en las obras del edificio (GIL SAURA, Yolanda, 2004, p. 234).

61 THOMSON LLISTERRI, Teresa, 1998, pp. 289-290.

62 El traslado del Santísimo al nuevo templo se produjo en 1735 (THOMSON LLISTERRI, Teresa, 2012).

${ }^{63}$ En las portadas de Mas de las Matas y Valjunquera se combinan las columnas salomónicas el empleo de los estípites. Los responsables de la primera fueron José y Francisco Dolz, quienes realizaron las obras entre 1734 y 1744 (GIL DOMINGO, Agustín, 1997, pp. 7-192); mientras que la autoría de la segunda se ha venido atribuyendo al escultor Juan Antonio Martín (PÉREZ TEMPRADO, Lorenzo, 1908; 1982, p. 16).

64 Tal y como se propone en GIL SAURA, Yolanda, 2004, p. 286, nota 37.

${ }^{65}$ El templo de Maleján fue levantado en la segunda mitad del Quinientos (CRIADO MAINAR, Jesús, 1997-1998, pp. 120-127), y

la venera se ha venido fechando para 1633 (AGUILERA HERNÁNDEZ, Alberto; ADEGO SEVILLA, Ramiro, 2013, p. 161, nota 118).

66 BENEDICTO GIMENO, Emilio, 1996, doc. 3, pp. 25-27.

67 IBÁÑEZ FERNÁNDEZ, Javier; MARTíN MARCO, Jorge, 2017, p. 296, y doc. 4, pp. 308-311. 

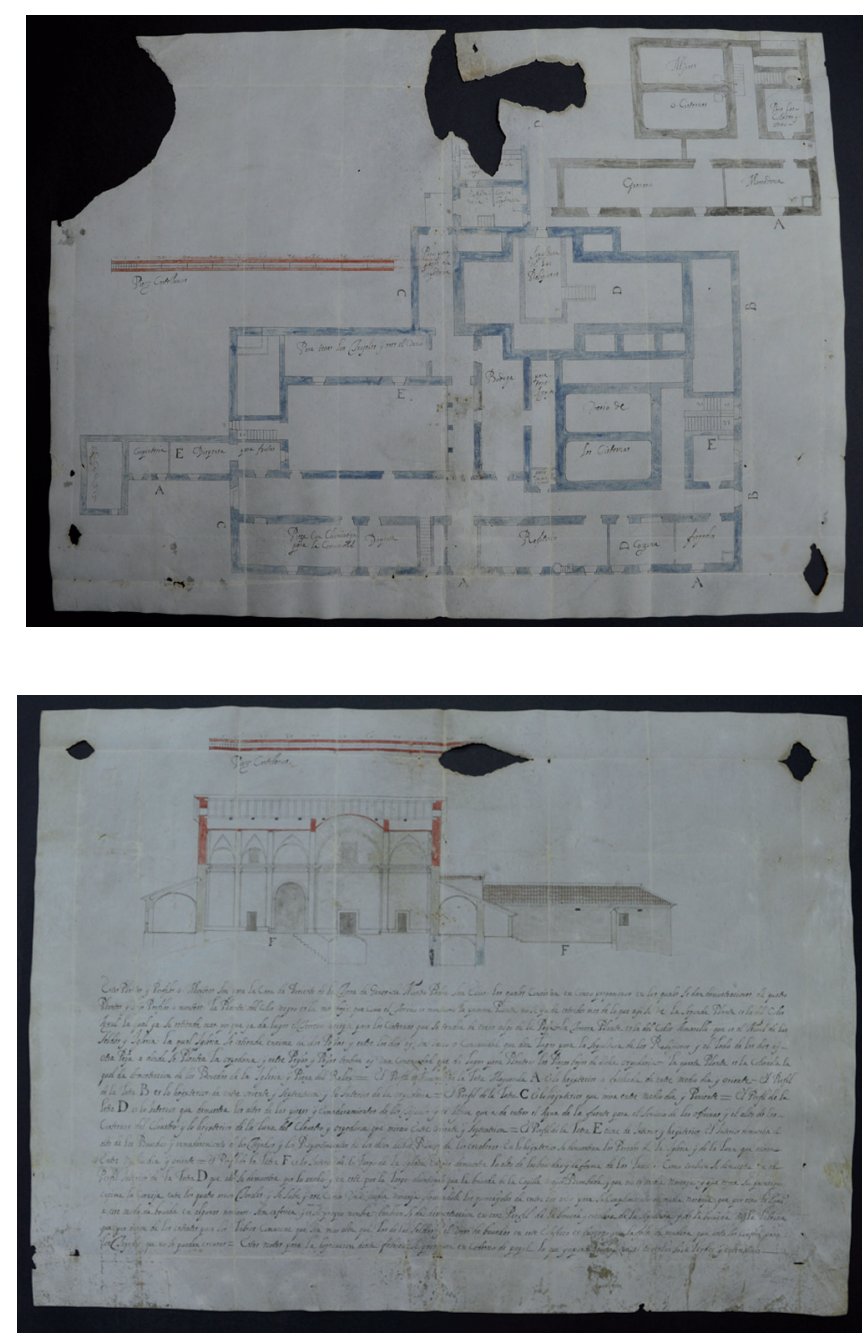

Figs. 5 y 6. Planta del convento del desierto de Calanda y sección de la iglesia. Archivo Municipal de Alcañiz, sección pergaminos.

localidad perteneciente la mitra zaragozana y el ejemplo más cercano al de Alcañiz. ${ }^{68}$ En cualquier caso, esta fórmula también se empleó para el cierre del coro alto y los brazos del transepto de la parroquial de Fortanete (Teruel) ${ }^{69} \mathrm{o}$ en el tramo de los pies de la iglesia de San Martín del Río (Teruel), que pudo realizarse en la reforma de la primera mitad del siglo XVIII. ${ }^{70}$

\section{El convento de carmelitas descalzos de San Elías de la Torre de Alginés, Ginés o del Desierto de Calanda}

La llegada de los frailes descalzos a la Torre de Alginés o Ginés, enclavada en las estribaciones de la sierra de La Ginebrosa (Teruel), junto a los ríos Guadalope y Mezquín, se produjo tras recibir los permisos pertinentes de las autoridades civiles en 1680. Ese mismo año, la Orden de Calatrava -propietaria del emplazamiento- cedió la torre a los monjes a treudo anual de seiscientos sesenta y seis sueldos y ocho dineros, y los descalzos acabaron instalándose en este enclave dos años después. ${ }^{71} \mathrm{El}$ conjunto, que se encontraba situado entre los términos de la ciudad de Alcañiz y las villas de Calanda y La Ginebrosa, distaba seis leguas media legua mas, o, menos de diversas localidades bajoaragonesas como Caspe, Híjar o Valderrobres, pero también la misma distancia de los núcleos castellonenses de Forcall, Morella o Herbés. ${ }^{72}$

Las obras del convento debieron de comenzar poco tiempo después. Pese a que el estudio de la documentación notarial ha arrojado escasos datos sobre su construcción, afortunadamente se conservan en el Archivo Municipal de Alcañiz dos diseños realizados sobre pergamino, uno correspondiente a la planta del convento [Fig. 5] y otro a la sección de la iglesia [Fig. 6], que fueron reaprovechados como guardas de los protocolos de Cosme Labrador -notario de Castelserás (Teruel)- correspondientes a los años $1712-1713$ y $1721,,^{73}$ y que constituyen dos ejemplos que se unen a la reducida

${ }^{68}$ Sobre este y otros ejemplos del ámbito valenciano, remitimos a GIL SAURA, Yolanda, 2004, p. 286.

69 GIL SAURA, Yolanda, 2014-2016, p. 131.

70 Para entonces, el concejo de la localidad solicitó permiso al Real Acuerdo para arrendar la primicia y destinar el producto a la reparación de una pared y para la construcción de un atrio [Archivo Histórico Provincial de Zaragoza (A.H.P.Z.), Real Acuerdo, Partido de Daroca, doc. 30, 1738].

71 CEAMANOS LLORENS, Roberto; MATEOS ROYO, José Antonio, 2005, p. 152.

72 (...) pareçio el padre fray Pedro de San Juan Baptista carmelita descalço del conbento de San Elias de la Torre de Gines sitio entre los terminos de la ciudad de Alcañiz villa de Calanda y villa de La Xinebrosa dicho conbento el qual dixo que por ciertos fines y efectos le importaba probar y verificar mediante personas fidedignas como dicho conbento esta a distancia de seis leguas media legua mas, o, menos los lugares infrascritos y siguientes la villa de Caspe, la villa de Samper, la villa de Hijar, Urrea de Yxar, Albalate del señor Arçobispo, el lugar de Ariño, Oliete, Cribillen, Gargallo, Julve, Las Cuebas de Cañarte, Bordon, El Orcajo, Morella, Erbes del señor, Peñarroya, Veceyte, Valde/28 r/robres, Queretas, Calazeite, y Maella (...) [A.H.P.A., Faustino Roque Gómez, notario de Calanda, 1683, ff. 27v-28r (Calanda, 2-II-1683)].

${ }^{73}$ El diseño de la sección de la iglesia fue publicado parcialmente en THOMSON LLISTERRI, Teresa, 2005, pp. 157-159. 
nómina de diseños arquitectónicos recopilados en la provincia de Teruel hasta el momento. ${ }^{74}$

La planta del complejo está realizada con tinta -de colores azul, negro y rojo- sobre pergamino y tiene unas medidas totales de 52,5 por 39,3 centímetros. Según la leyenda escrita en el anverso del otro pergamino, la zona coloreada en negro era la mas baja, que como el terreno [era] montuoso la primera planta no se puede estender mas de lo que ayi se veía, y se corresponde con la zona de aljibes y cisternas, cuarto para la colada y el horno, graneros y massaderia; mientras que la dibujada en azul se identifica con la segunda planta, que ya se estiende mas, por que ya da lugar el terreno [y] hacepte [que] para las cisternas que se tendra de tocar algo de la pe[n]ya.

El claustro habría de servir de elemento ordenador del complejo, ya que, tal y como aparece trazado, en torno a él debían construirse la bodega, el refectorio, la despensa, la pieza para la chimenea de la comunidad, otra despensa para los frutos y los trujales. Otras estancias, como la cocina o los fregaderos, debían instalarse en una zona un poco más alejada.

La sección de la iglesia quedó plasmada en un pergamino -de 53 por 49 centímetros- y muestra un templo de una sola nave, sin capillas laterales, con transepto no destacado en planta y cabecera recta, con el acceso situado en el brazo derecho del transepto. En el diseño que muestra la sección, se comprueba que el módulo basilical -dividido en tres tramos- y la cabecera se cubren con bóveda de cañón con lunetos, algo que, casi con toda probabilidad, también se planteó para los brazos del transepto, para cuya encrucijada se proyectó el volteo de una bóveda vaída; una estructura que, tal y como aparece anotado en la mitad inferior del pergamino, debía arrancar por encima [de] la cornija entre los quatro arcos torales y se sube y ase como una media naranja, y que habría de apoyarse en los quircayoles de entre los arcos para su conplimento de media naranja.
Las características arquitectónicas representadas en estos dos diseños responden de manera evidente a la tipología de desierto carmelita. ${ }^{75}$ Una de las particularidades que presentaban estas fundaciones es que su iglesia carecía de fachada monumental, ya que al templo se accedía desde el interior del recinto conventual -tal y como aparece dibujado en los pergaminos- y por tanto no era necesario situar el coro a los pies de la nave, sino que podía instalarse en cualquier punto. Tampoco se preveía la construcción de capillas laterales ni altares, porque estos solían disponerse alrededor de las cuatro crujías del claustro, un elemento que -generalmente- presentaba planta cuadrada y sobre el que se disponían las diferentes estancias de la fundación. ${ }^{76}$

En cualquier caso, las obras continuaron su curso, y los religiosos contrataron la realización del quarto de mediodía, el officio humilde -los servicios- y la cisterna del claustro con Pedro Cabarán -cantero de Alcorisa- el 20 de abril de 1697.77 E acuerdo prescribía la realización todas estas obras según había diseñado el tracista de nuestra sagrada religion, ${ }^{78}$ con los mismos materiales -mamposteria, cal y piedra-y del modo que estaban ejecutadas las paredes que al presente [estaban] hechas; todo ello de acuerdo al plan aprobado por el padre general fray Juan de la Concepción, y según las capitulaciones redactadas por el hermano fray Bernardo -la obra del combento- y fray Juan de San Juan Bautista -el estanque de la guerta de los arboles- en un plazo de seis años por cien escudos moneda valenciana.

Sin embargo, durante la Guerra de Sucesión, el convento se decantó por el bando austracista, lo que propició que sufriera graves daños infringidos por dos compañías borbónicas del mariscal Tesse al mando de Luis Ram. ${ }^{79}$ Poco tiempo después, los religiosos descalzos volvieron al convento con intención de reconstruirlo, aunque según una visita girada por la orden de Calatrava al enclave en 1719, donde se informa de las obras realizadas hasta el momento, la fábrica de la nueva iglesia todavía no se había iniciado, y hubo que esperar nueve años para que estuviera finalizada. ${ }^{80}$ Los frailes descal-

\footnotetext{
74 Con la salvedad, por ejemplo, de los diseños para la iglesia de Tronchón. Su estudio, en MARTín MARCO, Jorge, 2017-2018, pp. 225-242; y sobre su autoría, véase MARTín MARCO, Jorge, 2018, pp. 96-99.

75 Sobre esta tipología, remitimos a NARVÁEZ CASES, Carme, 2003, pp. 103-111.

76 NARVÁEZ CASES, Carme, 2003, p. 107.

77 A.H.P.A., Victorián Lázaro Gómez, notario de Calanda, 1697, ff. 99v-108v (Convento de la Torre de Ginés, Calanda, 20-IV1697). Documento referenciado en CEAMANOS LLORENS, Roberto; MATEOS ROYO, José Antonio, 2005, p. 152, nota 69.

78 A.H.P.A., Victorián Lázaro Gómez, notario de Calanda, 1697, f. 100r.

79 CEAMANOS LLORENS, Roberto y MATEOS ROYO, José Antonio, 2005, p. 152.

80 THOMSON LLISTERRI, Teresa, 2005, p. 157.
} 
zos, pese a la distancia que les separaba de Calan$\mathrm{da}$, prestaron determinados servicios a los habitantes de la localidad, como demuestra su oposición a que el convento de San Pascual Bailón de religiosos alcantarinos de Alcorisa fundase en la villa un nuevo hospicio en 1732, aunque finalmente el Real Acuerdo se opuso, ya que los descalzos habían conseguido licencia para ello y los alcantarinos ya tenían un establecimiento similar en su localidad. ${ }^{81}$ A raíz de la Desamortización de Mendizábal de 1835, fue abandonado, sus retablos fueron trasladados a ermitas e iglesias de la localidad -el mayor fue colocado en el templo del Pilar ${ }^{82}$ - y pasó a manos privadas en $1842 .{ }^{83}$

En cuanto a la actual iglesia del convento, sigue un esquema general de planta de cruz latina, con un módulo basilical de una nave dividida en cuatro tramos, que debieron de cubrirse con bóvedas de cañón con lunetos -actualmente se encuentran arruinadas-. Cuenta con coro situado a los pies, cuatro capillas - dos a cada lado de la nave- cubiertas con bóvedas de arista, y comunicadas entre sí, con transepto no acusado en planta -en cuya encrucijada se eleva una media naranja sobre pechinas- y con una cabecera de perfil recto. La fachada principal, situada a los pies del edificio, se realizó totalmente en piedra sillar, y se configura mediante un cuerpo central unido a otros dos laterales mediante unas volutas, con un acceso triple en forma de arcos de medio punto, una hornacina que acogía una imagen de San Elías -titular del convento- con las inscripciones VIVIT DOMINUS DEUS ISRRAEL -en la parte superior-y la abreviatura del lema de los carmelitas -ZELO ZELATUM SUM PRO DOMINO DEO EXERCITUUM- en la parte inferior; y flanqueada, asimismo, por dos vanos adintelados en cuya parte superior se ubica el escudo de la orden; todo rematado por un frontón triangular. La espadaña, situada en el lado izquierdo del templo, está construida en ladrillo y se compone de tres arcos de medio punto de diferente luz [Figs. 7 y 8 ].

El claustro está dispuesto junto al lado del Evangelio de la iglesia [Fig. 9]. Es de planta cuadrada y se articula mediante una serie de arquerías ciegas de medio punto -de piedra- y horadadas por unos vanos cuadrangulares y unos óculos que se abren en la parte superior. Las estancias distribuidas a su alrededor se encuentran prácticamente arruinadas, excepto la del lado Este, que cierra la cabecera de la iglesia y donde puede leerse en el dintel de un vano la inscripción JHS VINCIT REGNAT IMPERAT AB OMNI MALO NOS LIBERET ET DEFENDAT y el año 1701.

\section{Arquitectura para dos carismas}

Los dos edificios analizados en este estudio son los únicos que los carmelitas construyeron en el Bajo Aragón, y aunque cuentan con evidentes diferencias arquitectónicas, ya que cada uno pertenecía a una rama distinta de la orden, parte de sus historias constructivas coincidieron en el tiempo. Esta disparidad estilística se debe a que el orden calzado -Alcañiz- solía contratar a profesionales de la construcción externos para edificar los conventos, mientras que en el seno de los descalzos -Calanda- era habitual que los artífices perteneciesen a la orden.

La construcción del convento alcañizano fue llevada a cabo por maestros locales que probablemente siguieron trazas elaboradas por artífices asentados en ese medio. Por ejemplo, la cerca del convento fue contratada con Miguel Cubeles -que falleció en $1649^{84}$ - y con Miguel Olaso; este último, hijo de Domingo, un profesional de la construcción documentado en Muniesa (Teruel) desde finales del Quinientos, ${ }^{85}$ y que, casi con toda probabilidad, se encargó junto al propio Miguel y Francisco -otro de sus vástagos- de la construcción de la iglesia de la Purísima Concepción de Alloza (Teruel), ${ }^{86}$ localidad de la que se declararon habitantes cuando contrataron la realización de las bóvedas de la iglesia de los dominicos de Alcañiz en 1616. ${ }^{87}$ De estos tres miembros, el cabeza de familia -Domingo- aparece documentado en Zaragoza el 6 de abril de 1621, cuando traspasó a Juan de Urroz la fabrica del noviziado que realizaba en el convento de San Ildefonso de la ciudad del Ebro; ${ }^{88}$ y Francisco acabó contratando la construc-

81 CEAMANOS LLORENS, Roberto; MATEOS ROYO, José Antonio, 2005, p. 152.

82 ALLANEGUI Y LUSARRETA, Vicente, 1998, p. 289.

83 THOMSON LLISTERRI, Teresa, 2005, pp. 157-159.

${ }^{84}$ Archivo Parroquial de Alcañiz [A.P.A.], Quinqui Libris, 1646-1661, f. 508v (Alcañiz, 1-VII-1649).

85 ITURBE POLO, Guillermo; LORENZO MAGALLÓN, Isabel, 2017, p. 308.

${ }^{86}$ Antonio Ponz ya señaló que el arquitecto fue Olaso de Escatron [PONZ, Antonio, 1788, p. 189]; un dato que ha sido recogido por autores posteriores [BRIZ ISIEGAS, Gemma, 2008, p. 146].

87 GONZÁLEZ HERNÁNDEZ, Vicente, 1994, pp. 39-41.

${ }^{8}$ Una de las razones del traspaso es que Domingo tenía otras ocupaciones muy prezisas y que vivía fuera de Zaragoza [DE MIGUEL LOU, Gloria, 2005, p. 201]. 


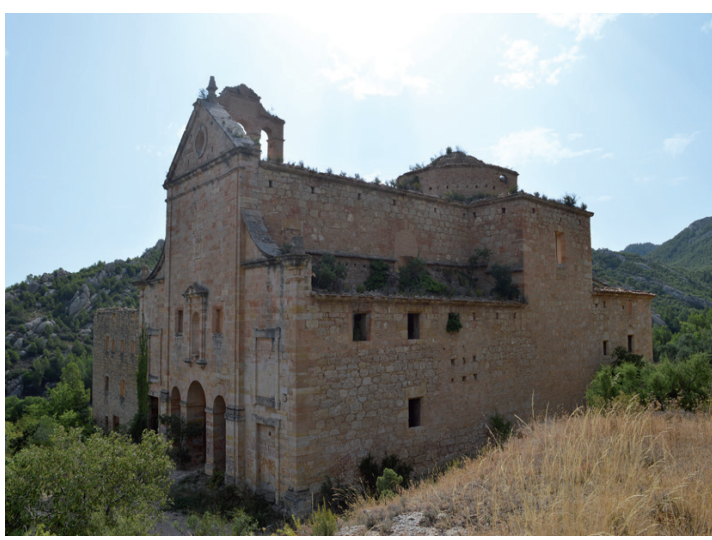

Fig. 7. Calanda, Teruel. Convento del Desierto. Exterior.

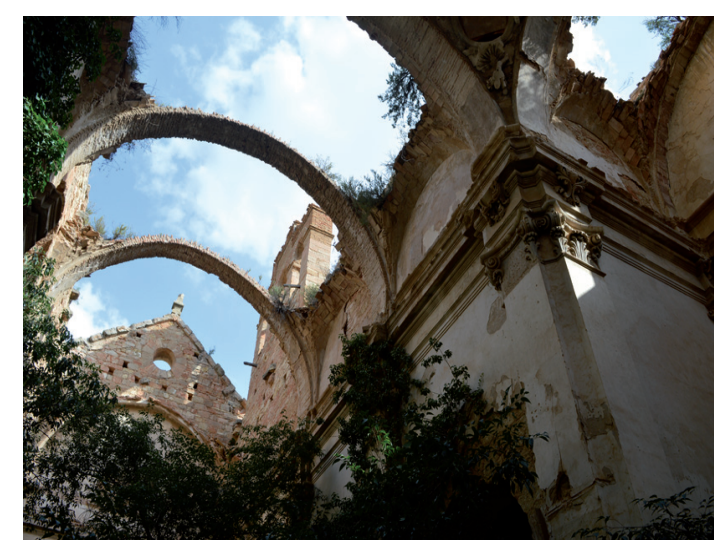

Fig. 8. Calanda, Teruel. Convento del Desierto. Interior. ción de la nueva iglesia parroquial de la Esperanza de Calanda el 30 de marzo de $1642 .{ }^{89}$

Los otros dos artífices conocidos de la obra, Antonio Estrada -que realizó la fachada, el coro y la torre- y Gerónimo Gascón -que culminó el último tramo de la iglesia-, son los descendientes de dos sagas de maestros de obras asentados en el Bajo Aragón desde las primeras décadas del Seiscientos. El primero era hijo del cantero francés Beltrán Estrada -documentado en Alcañiz desde 1630- y de su segunda mujer, y llegó a compaginar las obras de los carmelitas con las de la iglesia parroquial de Gandesa (Tarragona). ${ }^{90}$ Gascón, por su parte, era uno de los vástagos del maestro albañil Juan Gascón -y este, uno de los hijos del obrero de villa Pedro Gascón- que se encargó obras como la iglesia parroquial de San Nicolás de Bari de Las Parras de Castellote (Teruel) desde 1639, en la que también tomó parte Beltrán Estrada. ${ }^{91}$

En cuanto al caso calandino -que ha pasado desapercibido para los estudiosos de la arquitectura car- melita descalza ${ }^{92}$ - probablemente sus diseños fueran realizados por los tracistas de la orden. ${ }^{93} \mathrm{El}$ único contrato de obras que ha conseguido localizarse hasta la fecha -el del quarto de mediodía, el officio humilde y la cisterna del claustro ${ }^{94}$ - señala que estaba trazado y firmado -es decir, aprobadopor nuestro mui reverendo padre general frai Juan de la Concepcion, e incluso especificaba que el autor de la capitulación de la obra del convento había sido frai Bernardo, mientras que la del estanque de la guerta de los arboles fue redactada por el hermano frai Juan de San Juan Bautista. Su arquitectura resulta similar al de otros conventos descalzos aragoneses construidos tanto en ladrillo -Tarazona ${ }^{95}$ o Huesca ${ }^{96}$ - como la piedra -Boltaña $a^{97}$ y Valentuñana ${ }^{98}$ - durante los siglos XVII y XVIII.

Aunque las fuentes no son claras sobre el autor de los diseños del actual convento calandino, cabría la posibilidad de que hubieran sido realizados por fray Bernardo de San José, al que también identificamos como el autor de la capitulación para

89 CEAMANOS LLORENS, Roberto; MATEOS ROYO, José Antonio, 2005, p. 148.

90 MARTín MARCO Jorge, 2018, p. 103; MARTÍN MARCO, Jorge, 2019, pp. 35-53.

91 Los perfiles biográficos, en GONZÁLEZ HERNÁNDEZ, Vicente, 1994, pp. 153-154.

92 No aparece en los estudios de MUÑOZ JIMÉNEZ, José Miguel, 1990; ni de NARVÁEZ CASES, Carme, 2003.

93 Tal y como era lo habitual en los conventos descalzos (NARVÁEZ CASES, Carme, 1995, pp. 139-144; NARVÁEZ CASES, Carme, 2003, pp. 103-111; y NARVÁEZ CASES, Carme, 2006, pp. 237-254).

94 A.H.P.A., Victorián Lázaro Gómez, notario de Calanda, 1697, ff. 99v-108v (Convento de la Torre de Ginés, Calanda, 20-IV1697). Documento referenciado en CEAMANOS LLORENS, Roberto; MATEOS ROYO, José Antonio, 2005, p. 152, nota 69.

95 CARRETERO CALVO, Rebeca, 2012, pp. 409-504 (San Joaquín), y pp. 515-637 (Santa Teresa).

96 FONTANA CALVO, Celia, 1998, pp. 98-131.

97 LÓPEZ DUESO, Manuel, 2006, p. 209.

98 Asín GARCíA, Nuria, 2007, pp. 222-223. 


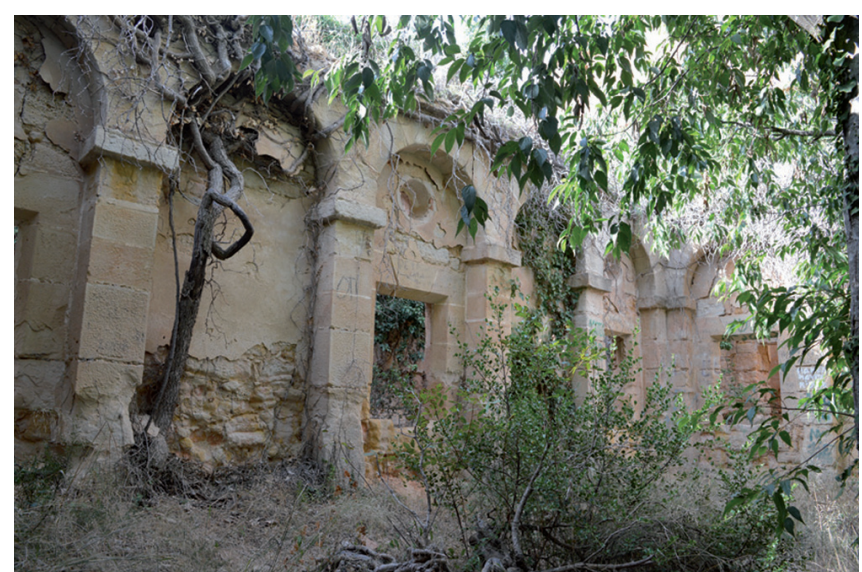

Fig. 9. Calanda, Teruel. Convento del Desierto. Claustro.

la obra del convento en 1697. Este religioso se encargó de los diseños del antiguo convento del Desierto de las Palmas en Benicasim; ${ }^{99}$ posteriormente se trasladó al convento de Tarazona, desde donde realizó un informe sobre la torre de la actual catedral de Tudela y probablemente las trazas para la capilla de Santa Ana de ese mismo templo en 1713. ${ }^{100}$ Poco tiempo después, se encargó -junto al hermano Juan de la Virgen- de realizar los diseños de la iglesia de Valentuñana entre 1715 y 1717; ${ }^{101}$ retornó a Calanda para visurar el campanario de la iglesia parroquial junto a Miguel de Aguas y Silvestre Escatron -probablemente Silvestre Colás ${ }^{102}$ - en $1721,{ }^{103}$ en las mismas fechas en las que se estaba construyendo la iglesia actual; y volvió a tierras navarras en los últimos años de su carrera profesional. ${ }^{104}$

Sin embargo, ambos conjuntos se encuentran en un lamentable estado de conservación. En el caso de la iglesia alcañizana, permanece cerrada al culto desde el año 2003, y su deterioro avanza a pasos agigantados, en gran parte, debido a las humedades. Todavía es más grave la situación del conjunto calandino, que presenta un estado deplorable y se acerca a la ruina total. Tan solo la acción humana podrá devolver el esplendor perdido a estos dos edificios tan importantes dentro del panorama arquitectónico del barroco bajoaragonés.

\section{Bibliografía}

AGUILERA HERNÁNDEZ, Alberto; ADIEGO SEVILLA, Ramiro. Maleján. Patrimonio artístico religioso. Borja: Centro de Estudios Borjanos, 2013.

ALLANEGUI Y LUSARRETA, Vicente. Apuntes históricos sobre la Historia de Calanda, edición de Ignacio Peiró. Calanda: Ayuntamiento de Calanda, Parroquia de la Esperanza de Calanda, Instituto de Estudios Turolenses, 1998.

ALMERÍA, José Antonio et alii. Las artes en Zaragoza en el último tercio del siglo XVII (1676-1696). Estudio documental. Zaragoza: Institución "Fernando el Católico", 1983.

ALQUÉZAR VILLARROYA, Cristina; LÓPEZ BIELSA, Rosario. Las iglesias parroquiales de la comarca de Andorra-Sierra de Arcos. Andorra: CELAN, Comarca de Andorra-Sierra de Arcos, 2014.

ARDID Y PLANO, Mariano. Memorias para escribir la historia de la ciudad de Alcañiz recogidas, compiladas y adiccionadas por don Mariano Ardid y Plano natural, y vecino de dicha ciudad. Alcañiz: 1852.

ASín GARCIA, Nuria. "La huella del barroco en las Cinco Villas". En: ASÍn GARCíA, N. (coord.). Comarca de las Cinco Villas. Zaragoza: Diputación General de Aragón, Departamento de Presidencia y Relaciones Institucionales, 2007, pp. 222-223.

AZANZA LÓPEZ, José Javier. "Tracistas y maestros de obras aragoneses en la arquitectura navarra". Boletín del Museo e Instituto "Camón Aznar", LXXI, 1998a, pp. 5-24.

AZANZA LÓPEZ, José Javier. Arquitectura religiosa del barroco en Navarra. Pamplona: Gobierno de Navarra, 1998b.

BARLÉS BÁGUENA, Elena. Arquitectura cartujana en Aragón (siglos XVII y XVIII) en el contexto de la provincia de Cataluña. Zaragoza: Institución "Fernando el Católico", 2014.

BENEDICTO GIMENO, Emilio. "Documentos sobre el convento y la ermita de San Roque de Calamocha". Xiloca, 18, 1996, pp. 15-45.

BRIZ ISIEGAS, Gemma. "Arquitectura religiosa: calvarios, ermitas, e iglesias parroquiales". En: ALQUÉZAR PENÓN, J.; RÚJULA LÓPEZ, P. (coords.) Comarca de Andorra-Sierra de Arcos. Zaragoza: Diputación General de Aragón, Departamento de Presidencia, y Relaciones Institucionales, 2008, pp. 139-154.

CARRETERO CALVO, Rebeca. Arte y arquitectura conventual en Tarazona en los siglos XVII y XVIII. Tarazona: Centro de Estudios Turiasonenses, 2012.

CEAMANOS LLORENS, Roberto; MATEOS ROYO, José Antonio. Calanda en la Edad Moderna y Contemporánea. Calanda: Instituto de Estudios Turolenses, 2005.

CRIADO MAINAR, Jesús. "La intervención de Alonso González en la edificación de las iglesias de Ribas, Albeta y Maleján (Zaragoza). 1555-1566". Cuadernos de Estudios Borjanos, XXXVII-XXXVIII-XXXIX-XL, 1997-1998, pp. 120-127.

99 GIL SAURA, Yolanda, 2004, p. 260.

100 AZANZA LÓPEZ, José Javier, 1998a, p. 17.

101 MUÑOZ JIMÉNEZ, José Miguel, 2017, pp. 479-506.

102 Colás se declaró vecino de la villa de Escatron cuando contrató, junto a Miguel de Aguas, las obras de la nueva colegiata de Alcañiz el 8 de abril de 1736 [THOMSON LLISTERRI, Teresa, 1998, doc. 34, pp. 325-337].

103 ALLANEGUI Y LUSARRETA, Vicente, 1998, p. 178.

104 AZANZA LÓPEZ, José Javier, 1998a, p. 17. 
DE MIGUEL LOU, Gloria. Las Artes en Aragón en el siglo XVII según el Archivo Histórico de Protocolos Notariales de Zaragoza. De 1619 a 1621, vol. III, Zaragoza, Institución "Fernando el Católico", 2005, doc. 33680 (4239), p. 110.

EIXARCH FRASNO, Josep. "Blay Berga, un personaje del siglo XVI, y el convento de PP. Dominicos de Forcall". En: Forcall y pueblos de la comarca dels Ports. Trabajos históricos, 1966-1993. Forcall: Ayuntamiento de Forcall, 1994, pp. 293-306.

FONTANA CALVO, Celia. Las clausuras de Huesca en el siglo XVII. Huesca: Ayuntamiento de Huesca, 1998.

FRANCO AUGUSTO, Jesús Manuel. "Colección de documentos artísticos procedentes del Archivo Histórico de Belchite". Aragonia Sacra, II, 1987, pp. 183-206.

GIL DOMINGO, Agustín. "Documentos inéditos de la fiel villa de Mas de las Matas". Boletín del Grupo de Estudios Masinos, 12, 1997, pp. 7-192.

GIL SAURA, Yolanda. Arquitectura barroca en Castellón. Castellón: Diputación de Castellón, 2004.

GIL SAURA, Yolanda. "El paisaje barroco de las Bailías: parroquias, ermitas y conventos". Baylías. Miscelánea del Centro de Estudios del Maestrazgo Turolense, 10, 2014-2016, p. 131

GONZÁLEZ HERNÁNDEZ, Vicente. Noticias histórico-artísticas de Alcañiz. Siglos XVII y XVIII. Alcañiz: Centro de Estudios Bajoaragoneses, 1994.

GRANDAS SAGARRA, Carme. "Arquitectura para una exposición: Barcelona 1929". Artigrama, 21, 2006, pp. 105-123.

GRANADOS BLASCO, Ma del Carmen. Las artes en Aragón en el siglo XVII según el Archivo de Protocolos Notariales de Zaragoza de 1637 a 1639, vol. IX. Zaragoza: Institución "Fernando el Católico", 2007, doc. 9-2589(2713), p. 243.

IBÁÑEZ FERNÁNDEZ, Javier. "Técnica y ornato: aproximación al estudio de la bóveda tabicada en Aragón y su decoración a lo largo de los siglos XVI y XVII". Artigrama, 25, 2010, pp. 363-405.

IBÁÑEZ FERNÁNDEZ, Javier. "De la crucería al cortado: importación, implantación y desarrollo de la bóveda tabicada en Aragón y su decoración a lo largo de los siglos XVI y XVII". En: ZARAGOZÁ, A.; SOLER, R.; MARÍN, R. (eds.). Construyendo bóvedas tabicadas. Actas del Simposio Internacional de Bóvedas Tabicadas. Valencia: Universitat Politécnica de Valencia, 2012, pp. 83-99.

IBÁÑNEZ FERNÁNDEZ, Javier. "La 'bóveda tabicada' en Aragon et l'évolution de son décor au cours du XVI siècle". En: CHATENET, M.; MINGOT, C. (eds.). Le Génie du lieu. La réception du langage classique en Europe (1540-1650): sélection, interprétation, invention. Actes des sixièmes Rencontres d'architecture européenne. Paris, 11-13 juin 2009. Paris: Picard, 2013, pp. 55-75.

IBÁÑEZ FERNÁNDEZ, Javier; CRIADO MAINAR, Jesús. "La arquitectura jesuítica en Aragón: estado de la cuestión". En: ÁLVARO ZAMORA, Ma I.; IBÁÑNEZ FERNÁNDEZ, J.; CRIADO MAINAR, J. (eds.) La arquitectura jesuítica. Zaragoza: Institución "Fernando el Católico", 2012, pp. 393-472.

IBÁÑEZ FERNANDEZ, Javier; MARTíN MARCO, Jorge. "Del salón al falso salón. Las reformas de la iglesia de Santo Domingo de Silos de Daroca (Zaragoza) durante la Edad Moderna". Artigrama, 32, 2017, pp. 287-317.

ITURBE POLO, Guillermo; LORENZO MAGALLÓN, Isabel. Historia del siglo XVI en Muniesa y su entorno. Muniesa: Centro de Estudios "Miguel de Molinos", 2017.
JULVE, Enrique y CUELLA, Ovidio. La villa de La Fresneda. Historia, monumentos, instituciones. La Fresneda: Ayuntamiento de La Fresneda, 1986.

LEÓN PACHECO, Carmen. Las artes en Aragón en el siglo XVII según el Archivo de Protocolos Notariales de Zaragoza. De 1628 a 1630, vol. VI. Zaragoza: Institución "Fernando el Católico", 2007, doc. 6-7943 (8774), pp. 130-139.

LÓPEZ DUESO, Manuel. "El arte entre los siglos XVI y XVIII". En: PALLARUELO CAMPO, S. (coord.). Comarca del Sobrarbe. Zaragoza: Diputación General de Aragón, Departamento de Presidencia y Relaciones Institucionales, 2006, pp. 207-218.

MARTíN MARCO, Jorge. "Instrumentos de representación gráfica y modelos tipológicos en la frontera entre Aragón, Valencia y Cataluña a caballo entre los siglos XVI y XVII". Aragonia Sacra, XXIV, 2017-2018, pp. 225-242.

MARTÍN MARCO, Jorge. "La circulación de maestros franceses entre las diócesis de Zaragoza y Tortosa durante los siglos XVI y XVII. El caso de Pedro Pizarro". Archivo de Arte Valenciano, XCIX, 2018, pp. 87-110.

MARTíN MARCO, Jorge. "Aportaciones documentales sobre los maestros de la iglesia de la Asunción de Gandesa (Tarragona) entre 1698 y 1701". Recerca, 18, 2019, pp. 35-53.

MARTÍNEZ ORTIZ, José. "Una fundación malograda: el colegio de los jesuitas de Alcañiz. Un interesante documento del siglo XVII". Teruel, 23, 1960, pp. 189-197.

MUÑOZ JIMÉNEZ, José Miguel. La arquitectura carmelitana (1562-1800): arquitectura de los carmelitas descalzos en España, México y Portugal durante los siglos XVI-XVIII. Ávila: Comisión Provincial del IV Centenario de la muerte de San Juan de la Cruz, 1990.

MUÑOZ JIMÉNEZ, José Miguel. "Tercera adenda al diccionario de artífices del Carmelo Descalzo". Monte Carmelo, vol. 125, 2, 2017, pp. 479-506.

NARVÁEZ CASES, Carme. "La gestació de l'estil arquitectònic carmelitá: les primeres disposicions dels descalços respecte a la construcció dels seus convents". Locus Amoenus, 1, 1995, pp. 139-144.

NARVÁEZ CASES, Carme. La arquitectura en la congregación de los carmelitas descalzos (siglos XVI-XVIII). Burgos: Monte Carmelo, 2003, pp. 103-111.

NARVÁEZ CASES, Carme. "Els espais conventuals i la seva projecció eremítica: el desert de Cardó". Recerca, 9, 2006, pp. 237-254.

PÉREZ TEMPRADO, Lorenzo. "De artistas y constructores". En: Boletín de historia y geografía del Bajo Aragón. Zaragoza: Mariano Escar, 1908 (Ed. facsimilar. Zaragoza: Centro de Estudios Bajoaragoneses, Ayuntamiento de Alcañiz-Ayuntamiento de Calaceite, 1982).

PONZ, Antonio. Viage de España, vol. XV. Madrid: Viuda de lbarra, hijos y compañía, 1788.

RINCÓN GARCÍA, Wifredo. "Aportaciones documentales al arte religioso en Aragón. 1688-1690". Aragonia Sacra, V, 1990, pp. 195-240.

SERLIO, Sebastiano. Tercero y qvarto libro de architectura de Sebastian Serlio Boloñes: En los quales se trata de las maneras de como se pueden adornar los hedificios: con los exemplos de las antiguedades. Agora nuevamente traduzido de Toscano en Romane CasteIlano por Francisco Villalpando architecto. Toledo: en casa de Ivan de Ayala, 1552, lib. IV.

TABOADA CABAÑERO, Eduardo Jesús. Mesa Revuelta. Apuntes de Alcañiz, edición de Antonio Beltrán. Alcañiz: Ayuntamiento de Alcañiz, 1969. 
THOMSON LLISTERRI, Teresa. Las artes en el Bajo Aragón en la primera mitad del siglo XVIII. Estudio documental. Alcañiz: Centro de Estudios Bajoaragoneses, 1998.

THOMSON LLISTERRI, Teresa. "El convento del Desierto de Calanda". En: MICOLAU ADELL, J. I.; THOMSON LLISTERRI, T. (eds.) Comarca del Bajo Aragón. Zaragoza: Diputación General de Aragón, Departamento de Presidencia y Relaciones Institucionales, 2005, pp. 157-159.

THOMSON LLISTERRI, Teresa. "La iglesia parroquial de San Bartolomé". En: Catálogo artístico, monumental y cultural. Alcañiz: Fundación Quílez Llisterri, 2012, http://www.fqll.es/catalogo_detalle.php?id=1130 (fecha de consulta: 13-IV-2019).

YEGUAS I GASSÓ, Joan. "Els Ochando. Una familia d'escultors barrocs amb lligams a Constantí". Estudis de Constantí, 28, 2012, pp. 39-48.

ZAPATER Y SANCHO, Pedro Juan. La Thesorera descubierta y vengada de las injurias del tiempo. Antigüedades $i$ excelencias de la insigne ciudad de Alcañiz. Alcañiz, copia del año 1704.

\section{Apéndice Documental}

\section{Documento $\mathrm{n}^{\circ} \mathrm{1}$}

1624, marzo, 6 Alcañiz

Miguel Olaso, domiciliado en la villa de Escatron, hallado en la de Alcañiz, reconoce que no se valdrá de una comanda anterior en caso de que Miguel Cubeles, albañil, vecino de Alcañiz, no le diere acabadas las tapias y paredes del convento de Nuestra Señora del Carmen de la villa de Alcañiz.

Archivo Histórico de Protocolos de Alcañiz [A.H.P.A.], Joan Thomas de Barberán, 1624, ff. 51 v-53 v.

[Al margen: Contracarta]

Eodem die et loco que yo Miguel Olaso domiciliado en la villa de Escatron de presente hallado en la villa $152 \mathrm{rl}$ [de] Alcañiz attendido que Miguel Cubeles albañil vecino de la dicha villa de Alcañiz me este tenido y obligado a dar y pagarme la cantidad de dos mil sueldos jaqueses y esto mediante instrumento publico de comanda fecho el presente dia de oy un poco antes de la presente y por el notario la presente recibiente y testificante recibido y testificado y aquella sea lisa y sin condicion halguna empero este pactado entre mi y dicho obligado de no valerme de aquella sino en el casso infrascrito por tanto de grado etc reconozco y confiesso y prometto convengo y me obligo que no me valdre de la dicha comanda ni executare aquella sino en casso que el dicho Miguel /52 v/ Cubeles obligado en la dicha comanda, o, los suyos en su casso, no me dieren acabadas y hechas las tapias y paredes del convento de Nuestra Señora del Carmen de la dicha villa de Alcañiz segun y conforme, y [d]entro el tiempo que entre los dos tenemos, tratado concertado y capitulado en un instrumento publico de capitulacion y concordia que entre nosotros esta hecho ottorgado y pactado testificado por el quondam Miguel Arbona notario publico y real y vecino que fue de dicha villa al chalendario de la qual me refiero etc y que no cumpliere por su parte lo contenido en dicha capitulacion, prometiente etc so obligacion etc fiat large etc.
Testes qui supra proxime nominati [Joan Royo y Joan Ainsa notario habitantes en Alcañiz].

\section{Documento $n^{\circ} 2$}

1624, marzo, 6 Alcañiz

Miguel Cubeles, albañil, vecino de la villa de Alcañiz, reconoce que no se valdrá de una comanda anterior ni la ejecutará salvo en el caso de que Miguel Olaso, albañil, vecino de la villa de Escatrón, no cumpla con su parte acerca de la obra y fábrica de las paredes y tapias que se han de hacer en el convento de Nuestra Señora del Carmen de Alcañiz.

A.H.P.A., Joan Thomas de Barberán, 1624, ff. 53v-55r.

\section{[Al margen: Contracarta]}

Eodem die et loco que yo Miguel Cubeles albañil vecino de la villa de Alcañiz attendido y considerado que $/ 54$ r/ Miguel Olaso albañil vecino de la villa de Escatron me este tenido y obligado a dar y pagarme la cantidad de dos mil sueldos jaqueses y esto mediante instrumento publico de comanda hecho un poco antes de la presente y por el mismo notario la presente recibiente testificante recibida y testificada y aquella sea lisa y sin condicion halguna, y este tratado entre mi y dicho obligado que no me he de valer de dicha comanda sino en el casso infrascrito por tanto de grado etc reconzco y confiesso y prometto convengo y me obligo que no me valdré de la dicha comanda ni exe/54 v/cutare aquella sino en casso que el dicho Miguel Olasso no cumpla por su parte con todo aquello que es tenido y obligado a hazer y cumplir conforme el thenor de una capitulacion y concordia que entre los dos tenemos hecha y pactada acerca de la obra [entre líneas: fabrica] [de las] paredes y tapias que se han de hazer en el convento de Nuestra Señora del Carmen de la dicha villa de Alcañiz que estan a mi cargo la qual dicha capitulacion fue fecha y testificada por el quondam Miguel Arbona notario publico y real y de los del numero de la dicha villa de Alcañiz al chalendario de la qual me refiero etc y particularmente en casso que el dicho Miguel Olasso no me diere y librare toda la madera, ladrillo /55 v/ y clavos necessarios para dicha obra y fabrica conforme el thenor de dicha capitulacion promettiente etc so obligacion etc fiat large etc.

Testes qui supra proxime nominatur [Joan Royo y Joan Ainsa notario habitantes en Alcañiz].

\section{Documento $\mathrm{n}^{\circ} 3$}

1629, junio, 27 Alcañiz

El convento de la madre de Dios del Carmen de la villa de Alcañiz se carga un censal de doscientos sueldos de pensión anual a favor de Miguel Valero, mercader, vecino de dicha villa, para proseguir con las obras de su convento.

A.H.P.A., Lorenzo Vililla, 1629, ff. 386r-389v.

[Al encabezamiento: Die XXVII mensis junii anno MDCXXVIIII Alcagnicii]. 
[Al margen: Censal extracta].

Eodem die que llamado convocado congregado y ajuntado en la manera acostumbrada el capitulo de los reverendos padres prior frayles y convento de la madre de dios del Carmen de la villa de Alcañiz por mandamiento del padre prior del dicho convento abajo nombrado y llamamiento de fray Geronimo Montañes sacristan de dicho convento el qual en pleno capitulo hizo fe y relacion a mi Lorenço Vililla notario infrascripto presentes los testigos abajo nombrados el demandamiento del dicho padre prior haver llamado y convocado el dicho capitulo a son de campana para la ora y lugar presentes et llegado y ajuntado el dicho capitulo dentro [de] la celda del dicho padre prior donde et segun que otras vezes etc en el qual /386 v/ dicho capitulo y en la congregacion de aquel intervinieron y fueron presentes los infrascriptos y siguientes et primo el padre fray Martin Sanchez del Castellar prior de dicho convento fray Angelo [espacio en blanco] suprior fray Phelipe de Aranda fray Eliseo Montañes fray Pedro Geronimo Cabañes fray Ertacio Royo fray Joan Bueno fray Miguel Segura fray Joan Ruiz y fray Diego Palau todo frayles profesos y conventuales en el dicho convento et de si fui de nos todo el dicho capitulo y convento capitulares etc los presentes por los absentes todos unanimes etc todos juntamente en nombre y voz del dicho capitulo y convento y con licencia a nosotros dada y concedida por nuestro padre provincial mediante una licencia firmada de su mano el qual es del tenor siguiente.

\section{$1387 r \mid$}

Frai Joan Pinto de Vitoria dotor en santa theologia y provincial de los carmelitas observantes en la provincia de Aragon, por quanto de parte del reverendo padre prior fray Martin Sanchez del Castellar y demas religiosos de nuestro convento de Alcañiz se nos ha representado la necessidad grande que tiene aquel convento de abitacion para los religiosos del, y por tener dos quartos empesados y no tener possibilidad para la prosecucion dellos y por padecer grande detrimento la obra les diessen y licencia para cargarse dozientas libras, por tanto usando de nuestra authoridad en quanto es de nuestra parte damos facultad para que se pueda cargar dichas dozientas libras en fe de lo qual mandamos hazer las presentes firmadas de nuestra mano y selladas con el sello de nuestro officio y referendadas de nuestro socio dadas en nuestro convento del Carmen de Valencia a 6 de febrero 1629.

[Suscripción autógrafa: Fray Juan Pinto de Vitoria provincial de Aragon].

\section{$1388 \mathrm{rl}$}

Con dicha licencia y por todos fines en aquella contenidos de grado etc certificados etc vendemos cargamos y originalmente imposamos etc a et en favor de vos Miguel Valero mercader vezino de la dicha villa de Alcañiz para vos y a los vuestros etc a saber es docientos sueldos dineros jaqueses y anua pension pagaderos en cada un año por el dia y fiesta del señor San Pedro Apostol que es a veynte y nueve dias del mes de junio dia dado y sera la primera paga de la dicha pension el dicho dia y fiesta del señor San Pedro Apostol del año primero viniente y que se contara de mil seyscientos y trenta

Et assi de alli adelante etc puestos $/ 388 \mathrm{v}$ y pagados a nuestras propias costas en las cassas de vuestra propia habitacion etc sin cargos de comiso ni fadiga empero con todos y qualesquiere otros drechos etc y esto sobredicho convento y sobre una guerta a el contigua el qual esta sitio en la dicha villa de Alcañiz y en el arrabal de ella confrenta con tres vias publicas con guerto de mossen Joan Exerique y con guerto de Joan Puche y sobre todos y quales quiere otros bienes y rentas del dicho capitulo y convento assi muebles como sittios etc los quales etc queriendo que la presente obligacion sea especial etc por precio es a saber de quatro mil sueldos dineros jaqueses los quales en poder y del dicho capitulo otorgamos haver recibido etc renunciantes etc mediante empero carta /389 r/ de gracia que a nosotros y los nuestros resercearnos de poder luyr y quitar el dicho y presente censal por otro tanto precio en una solucion y paga y en buena moneda fuera merecidos etc pagando las pensiones y prorrata leydas y costas hechas y hasi tenidas hasta el dia de tal luycion toda hora y quando quisieremos etc et vendemos cargamos e imposamos como dicho es el dicho y presente censal con salarios de procuradores y nuncios penas renunciaciones submisiones y con clausulas de execucion privilegiada execucion plenaria nomine precario constituto aprehension e inventariacion renunciacion de privilegios y gracias y con las demas clausulas y seguridades a vos dicho comprador y a los vuestros bien /389 v/ vistas y placientes et con esto el dicho fray Martin Sancho [sic] del Castellar prior juro en nombre y voz del dicho capitulo a Dios etc de pagar y no pleitear informar de derecho y so pena de perjuro etc y queremos que el presente censal sea reglado a consejo etc a todo provecho vuestro y de los vuestros etc no mudada la sustancia etc fiat large.

Testes Lorenzo Arcos notario y Domingo Ramon cantor Alcagnicii habitantes.

[Suscripción autógrafa: Fray Martin Sanchez del Castellar prior del convento de Nuestra Señora del Carmen en nombre y voz del dicho capitulo y convento otorgo lo sobredicho].

[Suscripción autógrafa: Yo Domingo Ramon soi testigo de lo sobredicho].

[Suscripción autógrafa: Yo Lorenço Arcos soy testigo de lo sobredicho].

\section{Documento $n^{\circ} 4$}

1695, abril, 5 Alcañiz

Antonio Estrada, cantero, vecino de la ciudad de Alcañiz, otorga haber recibido de Francisco Gazulla, do- 
miciliado en dicha ciudad, quinientas sesenta y seis libras, once sueldos y ocho dineros jaqueses, en parte de pago por la obra del frontispicio y coro de la iglesia del convento de Nuestra Señora del Carmen de dicha ciudad.

A.H.P.A., Pedro Juan Zapater y Sancho, 1695, ff. 182 $\mathrm{v}-183 \mathrm{r}$.

Documento referenciado en GONZÁLEZ HERNÁNDEZ, Vicente, 1994, p. 61, nota. 34

[Al encabezamiento: Die $\mathrm{V}$ mensis aprilis anno a $\mathrm{Na}$ tibitate domini MDCLXXXXV Alcagnitii]

[Al margen: Appoca extracta]

Eodem die que yo Antonio Estrada cantero vecino de la ciudad de Alcañiz de grado etc otorgo haber habido etc de Francisco Gazulla domiciliado en la dicha ciudad de Alcañiz a saber es la cantidad de quinientos sessenta y seis libras y onze sueldos y ocho dineros jaqueses los quales son a cuenta y en parte de pago de aquellas ochocientas libras jaquesas que el dicho Francisco Gazulla tiene obligacion de darme en virtud de una escritura de capitulacion hecha entre el capitulo de los prior frailes y conbento de Nuestra Señora del Carmen de dicha ciudad y Francisco Gazulla de una parte y yo dicho Antonio Estrada de la otra acerca de la obra del frontispicio y coro que ha de hazer en la iglesia de dicho conbento como de lo referido consta a lo largo por dicha escritura de capitulacion hecha en esta ciudad a veinte y siete de marzo del año mil seyscientos nobenta y tres y por el notario in/183 r/frascrito recibida y testificada y porque es verdad renunciante etc otorgo la presente apoca con inclusion de qualesquiere otras apocas asi publicas como privadas que asta el presente dia de oy tenga hechas y otorgadas en razon de dicha cantidad fiat large etc.

Testes Yldefonso Perez infanzon y Jusepe Yngles menor de dias maestro de hacer carros Alcagnitii habitantes.

[Suscripción autógrafa: Yo Antonio Estrada otorgo lo sobredicho].

[Suscripción autógrafa: Yo Ildefonso Perez soi testigo de lo sobredicho y lo firmo por Jusepe Ingles menor mi contestigo que dixo no sabia escribir].

Atesto que en el presente acto ay de enmendado donde dize, as, y que otro mas no ay que salbar segun fuero.

\section{Documento $n^{\circ} 5$}

1702, octubre, 10 Alcañiz

El prior, frailes y convento de Nuestra Señora del Carmen de la ciudad de Alcañiz y Francisco Gazulla, de una parte, y Antonio Estrada, cantero, vecino de dicha ciudad, de otra, declaran haber cumplido con sus obligaciones según ciertas capitulaciones A.H.P.A., Pedro Juan Zapater y Sancho, 1702, ff. 520v$524 r$.

[Al margen: Declaración extracta]

Eodem die mense anno et loco quibus supra que llamado conbocado congregado y ajustado en la forma y manera acostumbrada el capitulo de los prior, frailes y convento de Nuestra Señora del Carmen de la ciudad de Alcañiz por mandamiento del reverendo maestro frai Joseph La Pica prior de dicho convento y llamamiento de frai Francisco Perez religioso y llamador de aquel, el qual en pleno capitulo presentes los testigos infrascriptos hicieron fe y relacion a mi Pedro Juan Çapater y Sancho notario del numero de dicha ciudad, que de mandamiento de dicho padre prior havia llamado y congregado el dicho capitulo a son de campana como es costumbre para el dia, ora y lugar presentes, et asi junto dicho capi/521 r/tulo en la celda prioral de dicho convento donde et segun otras vezes etc en el qual dicho capitulo y en la congregacion de aquel, intervinimos y fuimos presentes los infrascriptos y siguientes: primo nos el dicho padre maestro frai Joseph la Pica prior, el reverendo maestro frai Elias Palacio, frai Domingo Zafon, frai Martin Monforte, frai Jacinto Ferrer, fray Pedro Ginoves, fray Gabriel Perez, fray Joseph Arias, frai Joseph Perez, fray Pedro Yranzo, fray Francisco Matheo, fray Miguel Ballestero y fray Severino Maioral, todos frayles profesos de dicho convento, et desi y los presentes por lo absentes etc en nombre y voz de dicho capitulo y Francisco Gazulla de una parte, et Antonio Estrada cantero de la $/ 521$ v/ parte otra habitantes en dicha ciudad de Alcañiz en dichos nombres, atendido y considerado hazerca [de] la obra del frontispicio y coro que se havia de hazer en dicho convento de Nuestra Señora del Carmen fue hecha capitulacion por la qual el dicho Antonio Estrada se obligo açer dicha fabrica y darla concluida y acabada en el dia veinte y uno de diciembre del año mil seiscientos noventa y quatro y por ella el dicho Francisco Gazulla bienhechor del dicho convento ofrecio darle la cantidad de ochocientas libras jaquesas en los plazos tiempos y con los pactos y condiciones en la escritura en razon de ello hecha contenida que hecha fue en esta ciudad a veinte y siete de marco del año mil seiscientos noventa y tres por el notario infrascripto testificada, los quales dichas ochocientas libras jaquesas consigno el dicho capitulo y convento al dicho Antonio /522 r/ Estrada en el dicho Francisco Gaculla para que de el las cobrara de una comanda de maior cantidad en que estava obligado en el mismo dia mes y año a favor del dicho capitulo y convento como por la asignacion de dicha cantidad si quiere contracarta y reconocimiento de dicha comanda pareze a lo largo que hecha fue en esta ciudad en poder del mismo notario los dichos dia, mes y año arriba calendados de la fecha de dicha capitulacion a que dichas partes se refirieron. Atendido y considerado acerca [de] la obra de la torre de las campanas que se havia de hazer en dicho convento fue [tachado: palabra ilegible] hecha otra capitulacion por la qual el dicho Antonio Estrada se obligo hazer dicha fabrica y darla concluida y acabada en el tiempo en ella señalado y por ella dicho capitu/522 v/lo y Francisco Gaculla ofrecieron dar al dicho Antonio Estrada la cantidad de doscientos y cinquenta libras jaquesas es a saber es el dicho capitulo cinquenta y el dicho 
Francisco Gacullas [sic] las doscientas en sus plazos y celebrar a su intersion diversas misas y a mas dio y asigno el dicho capitulo sitio suficiente al dicho Antonio Estrada para hazerse debaxo el coro un baso para enterrarse dicho Antonio Estrada y los de su casa y descendientes de sus hijos en diversos pactos y condiciones en la escritura en razon de ello hecha contenida que hecha fue en esta ciudad a diez y nuebe dias del mes de febrero del año mil seiscientos noventa y qua/523 r/tro y por el notario infrascripto recibida y testificada. Atendido despues por un banquillo que se conocio ser esencial y necesario para [/a] perfeccion de la dicha torre de las campanas fue trato y conzierto verbal que lo aria y añadiria dicho Antonio Estrada por ochenta libras jaquesas y los dichos capitulo y Francisco Gaculla se las pagarían en el discurso de dicha obra como por dicho trato y conzierto consta a que se refierieron y por quanto el dicho Antonio Estrada a cumplido enteramente en haver hecho las dichas obras y fabricas y dicho capitulo y Francisco Gaculla haver pagado el coste de ellas y haverse celebrado las dichas misas segun el tenor de las dichas y arriba mencionadas y calendadas capitulaciones tratos y conciertos verbales y es muy puesto en razon $/ 523 \mathrm{v} /$ se haga declaracion de ello. Por tanto de grado etc declaran y reconocen dichas partes haver cada una cumplido con lo que esta a su cargo en virtud de las capitulaciones, tratas y conciertos es a saber aviendo hecho el dicho Antonio Estrada dichas obras y fabricas y dicho capitulo y Francisco Gazulla pagado las cantidades en que aquellos fueron constituidos y a mas haverse celebrado dichas misas de que se dio el dicho Antonio Estrada por contento, satisfecho y pagado y a maior abundancia otorga apoca con la renunciacion dividida a favor del dicho capitulo y Francisco Gaculla de las cantidades que se obligaron a pagarle por razon de dichas obras y fabricas reconociendo dichas partes que ninguna de ellas a faltado en cosa alguna a lo que devia observar haver cumplido ambas con su obligacion juxta el tenor de dichas capitulaciones tratos y conciertos y con esto dichas partes reconocieron y confesaron lo sobredicho haver pasado asi y para que conste en todo tiempo de la verdad prometieron y se obligaron a ello con contravenir etc so obligacion que para ello hizieron de sus personas y todos sus bienes muebles y sitios etc los quales etc quirientes y de tal /524 r/ manera y con clausulas de execucion precario constituto aprehension emparamento, e, inventario y renunciacion y sometieronse etc quisieron fuese variado juicio etc fiat large.

Testes qui supra proxime nominatur.

[Suscripción autógrafa: Yo el maestro frai Joseph La Pica prior, en nombre y voz de dicho capitulo otorgo lo sobredicho].

[Suscripción autógrafa: Yo Antonio Estrada otorgo lo sobredicho].

[Suscripción autógrafa: Yo Francisco Gasulla otorgo lo sobredicho].

[Suscripción autógrafa: Yo Grabiel Dolz soi testigo de lo sobredicho y lo firmo por Juan Portoles mi contestigo que dixo no sabia escribir].

Atesto que en el presente acto ay de enmendados donde dize, c, siete, o, o, u, At, u, a, i, a, z, d, z, cono$c e, y$ un borrado entre las palabras fue, hecha, y que otro mas no ay que salbar segun fuero. 